more elevated point, the apparent colour of the spray became bluish.

September 5

\section{Circular Rainbow seen from a Hill-top}

Noticing a communication in NATURE (p. 36r) regarding the phenomenon of a circular rainbow, I thought it worth while to mention a case which lately came under my observation. Standing on a point of rock just epposite the beautiful falls of Montmorenci, Quebec, I was surprised to see a rainbow in the form of a circle passing through my feet. The spray from the falls was being blown into a deep cove in front of me, and the sun was high in the heavens behind. The primary was well defined and very beautiful ; the secondary was faint. I understand that the conditions for seeing this circular rainbow are not often favourable at Montmorenci ; still it may not be amiss to advise intending visitors not to stop at the bottom of the steps which lead down below the falls, but to clamber over the rocks as near the water as possible.

Montreal, August 28

\section{Intelligence in Frogs}

$\Lambda$ FRIEND in Scotland has a small lake in his grounds, which are surrounded by a high wall. At the bottom of the lake is a sluice by which the water can be let off into a burn below the grounds. A few weeks ago the lady of the house was walking down the road outside the wall towards the burn when, to her astonishment, she met a multitude of frogs making their way up the road, which makes a considerable detour, to the gate leading into the grounds. On inquiry she found that the lake had that morning been emptied through the sluice, and it was plain that these were frogs which, having been carried down with the water to the burn, were now making their way back to their old home. By what instinct did they know that the long road led to the point from which the short one had started? $B$. W. S.

September 3

\section{THE TEMPERATURE OF THE SOLAR SURF ACE}

THE power developed by the sun motor, recorded in NATURE, vol. xxix. p. 217 , has established relations between diffusion and energy of solar radiation. which prove that the temperature of the surface of the sun is extremely high. I have, therefore, during the summer solstice of 1884 , carried out an experimental investigation for the purpose of demonstrating the temperature of the solar surface corresponding with the temperature transmitted to the sun motor. Referring to the illustrations previously published, it will be seen that the cylindrical heater of the sun motor, constructed solely for the purpose of generating steam or expanding air, is not well adapted for an exact determination of the amount of surface exposed to the action of the reflected solar rays. It will be perceived on inspection that only part of the bottom of the cylindrical heater of the motor is acted upon by the reflected rays, and that their density diminishes graciually towards the sides of the vessel; also that owing to the imperfections of the surface of the reflecting plates the exact course of the terminal rays cannot be defined. Consequently, the most important point in the investigation, namely, the area acted upon by the reflected radiant heat, cannot be accurately determined. I have accordingly constructed an instrument of large dimensions, a polygonal reflector (see Fig. I), composed of a series of inclined mirrors, and provided with a central heater of conical form, acted upon by the reflected radiation in such a manner that each point of its surface receives an equal amount of radiant heat in a given time. The said reflector is contained within two regular polygonal planes twelve inches apart, each having ninety-six sides, the perimeter of the upper plane corresponding with a circle of eight feet diameter, that of the lower plane being six feet. The corresponding sides of these planes are connected by flat taper mirrors composed of thin glass silvered on the out- side. When the reflector faces the sun at right angles, each mirror intercepts a pencil of rays of 32.61 square inches section, hence the entire reflecting surface receives the radiant heat of an annular sunbeam of $32.61 \times 96=3130$ square inches section. It should be observed that the area thus stated is oor I less than the total foreshortened superficies of the ninety-six mirrors if sufficiently wide to come in perfect contact at the vertices. Fig. 2 represents a transverse section of the instrument as it appears when facing the sun; the direct and reflected rays being indicated by dotted lines. The reflector and conical heater are sustained by a flat hub and eight radial spokes bent upwards towards the ends at an angle of $45^{\circ}$. The hub and spokes are supported by a vertical pivot, by means of which the operator is enabled to follow the diurnal motion of the sun, while a horizontal axle, secured to the upper end of the pivot, and held by appropriate bearings under the hub, enables him to regulate the inclination to correspond with the altitude of the luminary. The heater is composed of rolled plate iron 0.017 inch thick, and provided with head and bottom formed of non-conducting materials. By means of a screw-plug passing through the bottom and entering the face of the hub the heater may be applied and removed in the course of five minutes, an important fact, as will be seen hereafter. It is scarcely necessary to state that the proportion of the ends of the conical heater should correspond with the perimeters of the reflector, hence the diameter of the upper end, at the intersection of the polygonal plane, should be to that of the lower end as 8 to 6 , in order that every part may be acted upon by reflected rays of equal density. This condition being fulfilled, the temperature communicated will be perfectly uniform. A short tube passes thrnigh the upper head of the heater, throngb which a thermometer is inserted for measuring the internal temperature. The stem being somewhat less than the bore of the tube, a small opening is formed by which the necessary equilibrium of pressure will be established with the external atmosphere. It should be mentioned that the indications of the thermometer during the experiment have been remarkably prompt, the bulb being subjected to the joint influence of radiation and convection.

The foregoing particulars, it will be found, furnish all necessary data for determining with absolute precision the diffusion of rays acting on the central vessel of the solar pyrometer. But the determination of temperature which uninterrupted solar radiation is capable of transmitting to the polygonal reflector calls for a correct knowledge of atmospheric absorption. Besides, an accurate estimate of the loss of radiant heat attending the reflection of the rays by the mirrors is indispensable. Let us consider these points separately.

Atmospheric Absorption. - The principal object of conducting the investigation during the summer solstice has been the facilities afforded for determining atmospheric absorption, the sun's zenith distance at noon being only $17^{\circ} 12^{\prime}$ at New York. The retardation of the sun's rays in passing through a clear atmosphere obviously depends on the depth penetrated; henceneglecting the curvature of the atmospheric limit-the retardation will be as the secants of the zenith distances. Accordingly, an observation of the temper ture produced $^{-}$ by solar radiation at a zenith distance whose secant is trice that of the secant of $17^{\circ} 12^{\prime}$, viz. $61^{\circ} 28^{\prime}$, determines the minimum atmospheric absorption at New York. The result of observations conducted during a series of years shows that the maximum solar intensity at $17^{\circ} 12^{\prime}$ reaches $66^{\circ} \cdot 2 \mathrm{~F}$, while at a zenith distance of $6 \mathrm{I}^{\circ} 28^{\prime}$ it is $52^{\circ} \cdot 5 \mathrm{~F}$.; hence, minimum atmospheric absorption at New York, during the summer solstice, is $66^{\circ} \cdot 2-52^{\circ} 5=13^{\circ} 7 \mathrm{~F}$, or $\frac{13.7}{66.2}=0.207$ of the sun's radiant energy where the rays enter the terrestrial atmosphere.

In order to determine the loss of energy attending the 